\title{
The Impact of Health Insurance on Healthcare Utilization by Migrant Workers in China
}

\author{
Fei Zhang ${ }^{1}$, Xinjie Shi ${ }^{2, *}$ and Yun Zhou ${ }^{2}$ \\ 1 College of Economics and Management, Zhejiang Normal University, Jinhua 321004, China, \\ zhangfeizju@126.com \\ 2 China Academy for Rural Development (CARD), School of Public Affairs, Zhejiang University, \\ Hangzhou 310058, China; zysimone@zju.edu.cn \\ * Correspondence: shixinjie1990@126.com or xjshi1990@zju.edu.cn
}

Received: 8 February 2020; Accepted: 10 March 2020; Published: 12 March 2020

\begin{abstract}
Health insurance is an essential instrument to ensure equal access to medical resources and promote the health of the general population. Robust evidence regarding whether migrant workers have benefited from available insurance schemes is limited. Drawing on survey data from the Rural Urban Migration in China (RUMiC) Project, this paper examines the effects of health insurance on migrant workers' utilization of routine medical services, the medical burden, and the utilization of preventive medical services using a two-part model, the Heckman model, the Tobit model, and a probit model. Our findings indicate that, first, participating in medical insurance increases migrant workers' probability of visiting a doctor. Unlike other medical insurance programs that positively affect migrant workers' medical expenditure, the new rural cooperative medical system fails to play an effective role. Second, participation in any medical insurance program effectively reduces migrant workers' medical burden and can improve the probability of preventive medical service utilization. Third, self-reported health and disease severity are pivotal to determining migrant workers' medical expenditure. Fourth, high-income people have a good health status and a lower probability of becoming ill and can afford relatively higher medical expenses once they become ill. China's medical insurance appears to mainly serve to reduce the financial burden for serious illnesses, reflecting important policy implications for policy-makers.
\end{abstract}

Keywords: medical insurance; healthcare service; migrant workers; China

\section{Introduction}

Since the 1980s, China has gradually established a new basic social health insurance (SHI) system in rural and urban areas, with the major types of insurance including the New Rural Cooperative Medical Scheme (NRCMS), which insures the large rural population; Urban Resident Basic Medical Insurance (URBMI), which targets urban workers in the informal sector and unemployed urban residents; and Urban Employee Basic Medical Insurance (UEBMI), which covers employees in the formal urban sector [1]. In 2009, the central government of China announced a comprehensive reform of the health system, with the ultimate goals of achieving universal coverage for basic healthcare and "establishing a basic healthcare system covering all the population by 2020" [2]. Since then, remarkable progress in health system reform has been achieved. By the end of 2011, more than $90 \%$ of the Chinese population was covered by the three main health insurance schemes described above, and the use of healthcare in general has increased significantly [3]. Furthermore, the proportion of out-of-pocket (OOP) payments among total medical expenditure decreased from $60 \%$ in 2000 to $40 \%$ and $28 \%$ in 2008 and 2016, respectively [4]. 
The migration of rural laborers into cities for employment has been one of the main driving forces of China's economic growth over the past three decades [5]. These migrants' health status is a key determinant of their earnings, especially for those engaged in labor-intensive jobs, since maintaining good physical health leads to a stable job, more work hours, and a better salary. However, due to their self-capacity and social policies, migrant workers tend to be stuck in the secondary labor market where they work and live in low-income environments, receive low earnings, engage in dirty and dangerous work, and are vulnerable to injuries and disease [6]. Good health and universal health coverage can be understood as a basic human right and a basic function of the government. By reducing the economic threshold for medical treatment and increasing the availability of medical services, medical insurance has a positive effect on national health and longevity.

Medical and resident health issues have been some of the most concerning problems for the government, scholars, and the general public in recent years. After 2003, with the establishment of a new national medical insurance system, most rural-to-urban migrant workers became qualified for one or more insurance schemes, such as the UEBMI, URBMI, NRCMS, commercial insurance, and/or other local insurance programs. However, robust evidence on whether migrant workers have benefited from these insurance schemes is limited. Meanwhile, the demographic dividend builds on health, reflecting the continuous advancement of China's industrialization and urbanization [7]. Therefore, this paper studies the relationship between the health of migrant workers and SHI utilization.

The rest of this paper is organized as follows. Section 2 provides a thorough literature review in the field of effects on SHI. Section 3 depicts the model specifications. Section 4 describes the data sources and provides the descriptive statistics for the key variables considered in our econometric estimation. Section 5 discusses the empirical results. The final section concludes the paper and provides recommendations for policy implementation in China.

\section{Literature Review}

Numerous studies have evaluated the effect of medical insurance implementation from two aspects: the medical service utilization effect and the health effect. Most studies have concluded that medical insurance can promote the utilization of medical services [8,9]. However, the findings on the health effect are controversial. For instance, by reviewing the literature on medical insurance, medical service utilization, and health from the past 25 years, Hadley (2003) found that, in some studies on mortality, having medical insurance can reduce the mortality rate by at least $4-5 \%$ [10]. In contrast, Finkelstein and McKnight (2008) found that the Medicare in the United States failed to significantly reduce the overall elderly mortality in its first 10 years [11].

Additionally, many studies have evaluated the implementation effects of UEBMI, URBMI, the NRCMS, commercial insurance, and other local insurance programs in China from different perspectives [12-15]. For example, Yang and Wu (2014) confirmed that the NRCMS has no effect on reducing OOP outpatient expenses [16]. Regarding the impact of China's medical insurance on the utilization of medical services among migrant workers, only few comprehensive studies have been conducted. Zhou et al. (2013) found that UEBMI and URBMI but not the NRCMS improved accessibility to preventive medical services for migrant workers, but UEBMI, URBMI, and the NRCMS enhanced routine medical service utilization [17]. Furthermore, Qin et al. (2014) confirmed that UEBMI played a prominent role in reducing the OOP ratio for migrant workers, thus increasing the number of physical examinations and improving their health status; NRCMS has significantly improved the health awareness of migrant workers and their utilization of preventive medical services [1].

The existing literature has not given sufficient attention to the utilization of SHI and medical services among migrant workers. Although the literature indicates that migrant workers are vulnerable in the current reform of the medical security system, little empirical evidence is available on migrant workers' participation in SHI and the effect of SHI on medical service utilization among migrant workers because collecting representative nationwide data on migrant workers is difficult. In addition, the construction of a medical insurance system for migrant workers remains under exploration. 
Based on above foundation, this paper studies the impact of medical insurance on migrant workers' annual medical expenditure, medical burden, and utilization of preventive medical services. Moreover, we believe that, compared with health effects, the effect of using medical services has more policy reference value for the following three reasons: (1) Promoting health is the ultimate goal of the medical and health system, but the factors affecting health extend beyond the system. Individual health is determined by a series of observable and unobservable individual characteristics and environmental factors, such as genetics, family income, and individual health behaviors. (2) The impact of SHI on health is indirect and uncertain, mainly reducing social risks rather than improving health, while the starting point of SHI is mainly to "improve the entire population's health status." (3) The health effect is related to the health indicators evaluated.

Therefore, this paper focuses on the effect of using medical services. Specifically, we propose the following relationships: (1) if SHI has a positive effect on medical expenditure, then SHI promotes migrant workers' utilization of routine medical services; (2) if SHI has a negative effect on the proportion of annual OOP medical expenditure, then SHI reduces the medical burden of migrant workers; and (3) if SHI has a positive effect on preventive medical services, then SHI promotes migrant workers' utilization of preventive medical services.

\section{Methods}

In reality, two cases involve zero medical expenditure: in one case, an individual is in good health and does not need medical services, and in the other case, due to the price of medical services or accessibility to medical services, medical expenses should be incurred but are not; that is, no medical expenses are incurred as a result of self-selection. Accordingly, referring to existing research, a two-part model (TPM) and the Heckman selection model are used to obtain unbiased estimates. The impact of medical insurance on the medical burden of migrant workers and their use of preventive medical services is based on the Tobit model and a probit model, respectively.

\subsection{TPM}

A TPM divides the generation of individual medical expenditure into two subprocesses: illness and attendance. The model assumes that the decision of whether to use medical services is a sequential and independent process. Specifically, the first part of the model predicts the probability of illness, which is specified as a probit model: $P\left(P_{i}=1\right)=P\left(\alpha_{1} I n s_{i}+\beta_{1} x_{i}^{\prime}+\varepsilon_{1 i}>0\right)$, where $P_{i}$ is a dummy variable equal to 1 if individuals are associated with nonzero medical expenditure and 0 otherwise. Ins represents the status of participating health insurance, and $x_{i}$ is a vector of individual characteristics such as age, sex, education, and income. We assume that $\varepsilon_{1 i} \sim N\left(0, \sigma^{2}\right)$, and we use a maximum likelihood method for the estimation.

The second part of the model is: $E\left[\log \left(y_{i} \mid P_{i}=1\right)\right]=\alpha_{2} I n s_{i}+\beta_{2} Z_{i}+\varepsilon_{2 i} E\left[\log \left(y_{i} \mid P_{i}=1\right)\right]=\alpha_{2} I N S_{i}+\beta_{2} Z_{i}+\varepsilon_{2 i}$ where $y_{i}$ denotes medical expenses and $Z_{i}$ is a vector of other independent variables besides medical insurance, $\varepsilon_{2 i} \sim N\left(0, \sigma^{2}\right) \varepsilon_{2 i} \sim N\left(0, \sigma^{2}\right)$.

The advantage of the TPM model is that it does not require the same set of covariates in both parts. Since some variables that affect the probability of visiting a doctor do not necessarily have an impact on medical expenditure, the two parts of the TPM model in this paper have different variables.

\subsection{Heckman Selection Model}

The sample selection model assumes that all the samples should have medical expenses, and zero medical expenses are the result of the sick samples choosing not to seek medical assistance. Such self-selection behavior will cause sample selection deviation. We use Heckman's (1979) two-stage method to resolve the problem [18]. 
At the first stage, the number of migrant workers choosing to receive treatment is taken as a binary dependent variable in the decision-making equation. The probability of migrant workers choosing to seek treatment can be constructed as a binary choice, shown as:

$$
\begin{gathered}
P_{i}^{*}=\gamma_{1} \operatorname{In} s_{i}+\lambda_{1} x_{i}^{\prime}+\mu_{1 i}>0, P_{i}=1 ; \text { otherwise, } P_{i}=0 \\
P_{i}=1, \log y_{i}=\gamma_{2} \operatorname{In} s_{i}+\lambda_{2} z_{i}^{\prime}+\mu_{2 i} \\
\mu_{1 i}, \mu_{2 i} \sim N\left(0, \sigma^{2}\right) \cdot P_{i}=1 P_{i}=0
\end{gathered}
$$

\subsection{Tobit Model}

Since the value of medical burden ranges from 0 to 1 , OLS can result in estimation bias. Therefore, we employed the Tobit model to estimate the function: $y_{i}^{*}=\beta^{T} x_{i}+e_{i}, e_{i} \sim N\left(0, \sigma^{2}\right), i=1,2, \ldots, n$, $y_{i}=y_{i}^{*}$ if $y_{i}^{*}>0, y_{i}=0$, if $y_{i}^{*} \leq 0$, where $y_{i}^{*}$ is the latent dependent variable, $x_{i}$ is a vector of independent variables that affect migrant workers' medical burden, and $y_{i} y_{i}$ is the migrant workers' financial burden of treatment.

\subsection{Probit Model}

Similar to the utilization of formal medical services, the demand for preventive medical services is also caused by the demand for health. However, the obvious difference between preventive medical services and formal medical services is that the consumption of preventive medical services does not improve individual health immediately because of a lag effect. Because the occurrence of disease is random, the consumption of preventive medical services can reduce the incidence of disease and have an impact on the marginal yield rate of formal medical services, and the importance of preventive healthcare has received increasing attention.

The binary probit model for migrant workers' utilization of preventive medical services is:

$$
P_{i}^{*}=\alpha \operatorname{Ins} s_{i}+\beta z_{i}^{\prime}+\mu_{i} \text {, if } \alpha \operatorname{Ins} s_{i}+\beta Z_{i}^{\prime}+\mu_{i}>0, \text { then } P_{i}=1,
$$

where $P_{i}^{*}$ is the probability of migrant workers seeking preventive medical services, Ins $s_{i}$ represents the status of participating in health insurance, and $Z_{i}$ is a vector of other independent variables.

\section{Data}

\subsection{Data Source}

We used survey data from the Rural Urban Migration in China (RUMiC) Project to comprehensively examine the impact of health insurance participation on the migrant worker population. This project is a national survey designed by a team of international researchers from China and Australia. This project aims to investigate the income, social welfare, quality of life, and other living conditions of rural-urban migrants [19]. The RUMiC Project was conducted in 2008 and 2009 in 15 different cities with a relatively high concentration of migrants distributed in nine provinces and municipalities of China. Presently, the RUMiC database is considered one of the best national survey databases on rural-urban migration in China [20]. More information on the design, sampling procedures, and methodology of this project has been documented elsewhere [21,22]. For the purposes of the study, migrant workers between 16 and 65 years old were selected as the research objects. After the elimination of missing values and extreme outliers, 7300 valid samples were obtained.

Of the total sample, $35.15 \%$ (sample size: 2566) did not incur any medical expenses in the year; for the 4734 migrant workers who incurred medical expenses, 150 were completely covered for medical expenses, 4188 covered medical expenditure completely at their own expense, and another 546 reported different levels of medical subsidies; that is, $7.48 \%$ of the total sample received medical subsidies. The annual average medical expenditure of the entire sample was 574.08 yuan, and the annual average medical expenditure of the sick sample was 885.25 yuan. Of the total sample, $15.04 \%$ had experienced 
illness in the past three months, $13.75 \%$ had incurred medical expenses in the past three months, and $25.55 \%$ had received a physical examination or been immunized. For those who were sick in the past three months, $45.76 \%$ chose to take medicine, $13.13 \%$ went to an infirmary or small clinic to see a doctor, and $18.23 \%$ went to a hospital to see a doctor. The proportion of seriously ill migrant workers (sample size: 306 ) who chose to go to the hospital was only $38.24 \%$.

\subsection{Variable Specification}

The dependent variables selected for our analysis were (1) formal medical utilization, where "total medical expenditure in the previous year" was used for measurement; (2) migrant workers' financial burden of treatment, where the ratio of OOP payments among total medical expenditure in the previous year was used for measurement; and (3) preventive medical service utilization, which was measured by "whether a migrant worker had any physical exams in the previous year."

Regarding the variable of interest-health insurance-two situations are described in the literature: one is the setting of a binary variable of whether a migrant worker participates in any health insurance program, and the other is the setting of multiple classified variables, that is, the specific health insurance program in which migrant workers participate. We follow the second approach because participation policies, reimbursement mechanisms and the financing levels of various types of health insurance are different. If we simply treat health insurance as a binary variable, the difference between the effects of different types of health insurance will be hidden. Therefore, according to the condition of sample migrant workers' participation in health insurance, a categorical variable called "type of medical insurance" was constructed, and responses ranged from 0 to 5 , representing "no insurance," "insured by NRCMS," "insured by employment medical care," "insured by public health services" ("paid for by the government"), "insured by other single medical insurance" (insured by one program that has not been mentioned above)," and "multiple insurance" ("insured by more than one medical insurance program"), respectively.

Aside from the indicator of health insurance status, we also considered a set of factors that may influence the dependent variables, as summarized in Table 1. These factors included age, sex, education, family income, health status, and morbidity, as commonly used in the literature. We used self-rated health (SRH) to present the health status of migrant workers, which is classified into five levels [23], and other studies show that such a subjective health rating is a good indicator of a respondent's actual health status. Regarding morbidity, migrant workers were asked, "Were you sick or injured in the last three months? (including chronic or acute disease)"; according to their responses, morbidity was categorized into three levels: 1 represented slightly or not sick, 2 represented fairly sick, and 3 represented seriously sick. Hukou is one of the institutional barriers in the current insurance platforms that affects migrant workers' participation and use of insurance [1]. According to the RUMiC Project, hukou was categorized into two types: 1 represented local rural household registration, and 2 represented migrant rural household registration. Long working hours had significant adverse effects on most health outcomes, and long working hours were associated with a depressive state, anxiety, sleep conditions, and coronary heart disease [24]. Therefore, these variables were also considered.

\subsection{Descriptive Statistics}

Table 1 reports the descriptive statistics for the sample. A total of $65.95 \%$ of the migrant workers were covered by a single insurance program, $3.81 \%$ were covered by two or more types of insurance, and $30.25 \%$ did not have any medical insurance. When asked about the reasons for not having medical insurance, $35 \%$ of the uninsured workers believed that insurance is not necessary to purchase, $27 \%$ did not know the details of medical insurance, and 16\% could not afford the expense. 
Table 1. Sample summary statistics for the selected variables.

\begin{tabular}{|c|c|c|c|c|c|}
\hline Variable & Definition & Overall & Percent (\%) & Mean & Std. Dev. \\
\hline Total medical expenditure & $\begin{array}{l}\text { Individual total medical expenditure in the } \\
\text { previous year (yuan) }\end{array}$ & 7300 & & 574.08 & 2897.95 \\
\hline Nonzero medical expenses & $\begin{array}{l}\text { Individual total medical expenditure in the } \\
\text { previous year above zero (yuan) }\end{array}$ & 4734 & & 885.25 & 3560.285 \\
\hline Medical burden & & 4584 & & 0.95 & 0.164 \\
\hline \multirow{2}{*}{ Preventive medical service utilization } & $1=$ Yes & 1865 & 25.55 & & \\
\hline & $2=\mathrm{No}$ & 5435 & 74.45 & & \\
\hline \multirow{6}{*}{ Type of medical insurance } & $0=$ No health insurance & 2208 & 30.25 & & \\
\hline & $1=$ NRCMS & 4035 & 55.27 & & \\
\hline & $2=$ employment medical care & 337 & 4.62 & & \\
\hline & $3=$ public health services & 162 & 2.22 & & \\
\hline & $4=$ other single medical insurance & 280 & 3.84 & & \\
\hline & $5=$ multiple insurance & 278 & 3.81 & & \\
\hline SRH & $\begin{array}{c}\text { Self-rated health } \\
(0=\text { poor, } 4=\text { excellent })\end{array}$ & 7300 & & 3.10 & 0.754 \\
\hline \multirow{3}{*}{ Morbidity } & $1=$ Not sick or slightly sick & 6389 & 87.52 & & \\
\hline & $2=$ Fairly sick & 605 & 8.29 & & \\
\hline & $3=$ Seriously sick & 306 & 4.19 & & \\
\hline Sex & $\begin{array}{c}\text { Dummy variable } \\
(1=\text { male, } 0=\text { female })\end{array}$ & & & 0.57 & 0.495 \\
\hline Age & Range of 16 to 65 years old & 7300 & & 32.29 & 10.293 \\
\hline \multirow[t]{2}{*}{ Marital status (\%) } & Married & 4753 & 65.11 & & \\
\hline & Unmarried & 2547 & 34.89 & & \\
\hline \multirow{5}{*}{ Education } & $0=$ Elementary school and below & 1158 & 15.86 & & \\
\hline & 1 = Middle school & 3272 & 44.82 & & \\
\hline & $2=$ High school & 1605 & 21.99 & & \\
\hline & $\begin{array}{c}3=\text { Vocational senior secondary } \\
\text { school/specialized secondary school }\end{array}$ & 840 & 11.51 & & \\
\hline & $4=$ Polytechnic college and above & 425 & 5.82 & & \\
\hline Family income & Annual household income (yuan) & 7300 & & 2766.40 & 1685.271 \\
\hline Working hours & Working hours per week on average (hour) & 7300 & & 61.15 & 21.543 \\
\hline \multirow{2}{*}{ Hukou status } & $0=$ Migrant rural household registration & 5911 & 80.97 & & \\
\hline & $1=$ Local rural household registration & 1389 & 19.03 & & \\
\hline \multirow{3}{*}{ Region } & $0=$ Eastern China & 3788 & 51.89 & & \\
\hline & $1=$ Central China & 2250 & 30.82 & & \\
\hline & $2=$ Western China & 1262 & 17.29 & & \\
\hline
\end{tabular}

Among the sample participants in a single medical insurance program, the NRCMS was the most common insurance held $(55.27 \%)$, while the other types of medical insurance with a high participation rate included employment medical care $(4.62 \%)$ and public health services $(2.22 \%)$. The total number of migrant workers participating in the NRCMS accounted for $58.58 \%$ of the sample (including people with multiple insurance programs). The main reason for the high proportion of participation in the NRCMS is that opinions on the establishment of the new rural cooperative medical care system clearly stipulate that the NRCMS must regard a family as a unit of participation. The implementation policy assumes that "a village can leak households, but households do not leak people." Although many migrant workers leave the countryside to work in cities, they still participate in the NRCMS, which may ensure that other family members can benefit from the NRCMS.

\section{Empirical Results}

Tables $2-5$ report the main estimation results. Table 2 reports the TPM regression results for migrant workers' medical expenditure. Table 3 reports the regression results of the Heckman selection 
model. Table 4 reports the Tobit regression results for migrant workers' medical burden. Table 5 reports probit regression results for migrant workers' utilization of preventive medical services.

Table 2. The TPM regression results for migrant workers' medical expenditure.

\begin{tabular}{|c|c|c|c|}
\hline Variable & Variable Types & Probability of Migrant Workers' Consultation & Medical Expenditure \\
\hline \multirow{9}{*}{ Medical insurance } & Insured by NRCMS & $0.0987^{* * *}$ & $-0.1321 * * *$ \\
\hline & & $(0.0361)$ & $(0.0447)$ \\
\hline & Employment medical care & 0.1973 ** & $0.2158^{* *}$ \\
\hline & & $(0.0795)$ & $(0.0890)$ \\
\hline & Public health services & 0.1581 & -0.0784 \\
\hline & & $(0.1159)$ & $(0.1476)$ \\
\hline & Other single medical insurance & 0.0940 & $0.1965^{*}$ \\
\hline & & $(0.0854)$ & $(0.1053)$ \\
\hline & Multiple insurance & $\begin{array}{c}0.2516^{* * *} \\
(0.0904)\end{array}$ & $\begin{array}{c}0.4116^{* * * *} \\
(0.1045)\end{array}$ \\
\hline SRH & & $\begin{array}{c}-0.1817^{* * * *} \\
(0.0230)\end{array}$ & $\begin{array}{c}-0.2776 * * * \\
(0.0283)\end{array}$ \\
\hline \multirow[t]{2}{*}{ Morbidity } & Fairly sick & $\begin{array}{c}1.3565 * * * \\
(0.0937)\end{array}$ & $\begin{array}{c}0.5152 * * * \\
(0.0606)\end{array}$ \\
\hline & Seriously sick & $\begin{array}{c}2.3421 * * * \\
(0.3412)\end{array}$ & $\begin{array}{c}1.4978^{* * * *} \\
(0.0791)\end{array}$ \\
\hline Sex & & $\begin{array}{c}-0.0586^{*} \\
(0.0328)\end{array}$ & $\begin{array}{c}-0.1645^{* * *} \\
(0.0407)\end{array}$ \\
\hline Marital status & & $\begin{array}{c}0.0230 \\
(0.0446)\end{array}$ & $\begin{array}{c}0.0817 \\
(0.0552)\end{array}$ \\
\hline \multirow[t]{4}{*}{ Age } & & 0.0023 & $0.0095^{* * *}$ \\
\hline & & $(0.0021)$ & $(0.0027)$ \\
\hline & Junior high school & $0.1119^{* *}$ & 0.0174 \\
\hline & & $(0.0488)$ & $(0.0648)$ \\
\hline \multirow{5}{*}{ Education } & High school & $\begin{array}{c}0.1555 * * * \\
(0.0550)\end{array}$ & $\begin{array}{c}0.0976 \\
(0.0712)\end{array}$ \\
\hline & Technical secondary school & $0.2026^{* * *}$ & $\begin{array}{c}(0.0712) \\
0.1138\end{array}$ \\
\hline & & $(0.0669)$ & $(0.0847)$ \\
\hline & Junior college & $0.2911^{* * *}$ & 0.0531 \\
\hline & & $(0.0832)$ & $(0.0993)$ \\
\hline \multirow[t]{2}{*}{ Ln (family income) } & & $-0.0596 * *$ & $0.0959 * * *$ \\
\hline & & $(0.0277)$ & $(0.0360)$ \\
\hline \multirow[t]{2}{*}{ Ln (work time) } & & 0.0133 & - \\
\hline & & $(0.0191)$ & - \\
\hline \multirow[t]{3}{*}{ Hukou } & & -0.0053 & - \\
\hline & & $(0.0459)$ & - \\
\hline & Central & $0.1646^{* * *}$ & $-0.2854^{* * *}$ \\
\hline \multirow{5}{*}{ Region } & & $(0.0394)$ & $(0.0485)$ \\
\hline & Western & $0.3989^{* * *}$ & $-0.3785^{* * *}$ \\
\hline & & $(0.0509)$ & $(0.0563)$ \\
\hline & Intercept & $0.8773 * * *$ & $5.2987^{* * *}$ \\
\hline & & $(0.2444)$ & $(0.3066)$ \\
\hline $\mathrm{N}$ & & 7300 & 4734 \\
\hline Pseudo $R^{2} /$ Adj & & Pseudo $R^{2}=0.0916$ & Adj R-squared $=0.1447$ \\
\hline Wald $\chi^{2}$ & & $460.27^{* * *}$ & - \\
\hline $\mathrm{F}$ & & - & 50.87 \\
\hline
\end{tabular}

Note: NRCMS represents the New Rural Cooperative Medical Scheme; SRH represents self-rated health. The reference for "medical insurance" is "no medical insurance." The references for disease severity, sex, marriage, education, Hukou, and region are "not sick or slightly sick," "female," "unmarried," "elementary school and below," "rural household registration," and "eastern China," respectively. *, **, and ${ }^{* * *}$ indicate significance at levels of $10 \%$,

$5 \%$, and $1 \%$, respectively. The variables in Tables $3-5$ have the same definitions.

\subsection{TPM Regression Results for Migrant Workers' Medical Expenditure}

Table 2 reports the TPM regression results for migrant workers' medical expenditure. We first focus on the impact of various types of medical insurance. After controlling for other variables, employment medical care, the NRCMS, and repeated participation in insurance had significantly positive effects on increasing the probability of migrant workers' seeking medical consultations. While these items had significantly different effects on migrant workers' medical expenditure, the coefficient of the NRCMS was negative and statistically significant; in contrast, the coefficients of employment medical care, other medical insurance, and repeated participation in medical insurance were positive and statistically significant, especially for repeated participation in medical insurance. The possible 
reasons are that the NRCMS requires migrant workers to cover their medical expenses and receive reimbursement after returning to their hometowns, which is a cumbersome reimbursement procedure for migrant workers, and migrant workers have little knowledge about the NRCMS, such as the reimbursement ratio, reimbursement procedures, and reimbursement restrictions. Compared with the NRCMS, other insurance programs have no reimbursement procedures in different places. Additionally, repeated participation in medical insurance expands the reimbursement range. Therefore, participation in insurance-except for the NRCMS - significantly improves migrant workers' utilization of routine medical services.

Table 3. Heckman selection model of migrant workers' medical expenditure.

\begin{tabular}{|c|c|c|c|}
\hline Variable & Variable Types & Medical Expenditure & Decisions for Medical Expenditure \\
\hline \multirow{10}{*}{ Medical insurance } & NRCMS & -0.0205 & $0.0987^{* * *}$ \\
\hline & & $(0.0749)$ & $(0.0361)$ \\
\hline & Employment medical care & $0.4268^{* * *}$ & $0.1973^{* *}$ \\
\hline & & $(0.1587)$ & $(0.0796)$ \\
\hline & Public health services & 0.1116 & 0.1581 \\
\hline & & $(0.2037)$ & $(0.1129)$ \\
\hline & Other single medical insurance & 0.3003 * & 0.0940 \\
\hline & & $(0.1584)$ & $(0.0842)$ \\
\hline & Multiple insurance & $0.6787^{* * *}$ & $0.2516^{* * *}$ \\
\hline & & $(0.1741)$ & $(0.0891)$ \\
\hline \multirow[t]{2}{*}{ SRH } & & $-0.4520 * * *$ & $-0.1817^{* * *}$ \\
\hline & & $(0.0694)$ & $(0.0229)$ \\
\hline \multirow[t]{4}{*}{ Morbidity } & Fairly sick & $1.5777^{* * *}$ & $1.3565^{* * *}$ \\
\hline & & $(0.3446)$ & $(0.0929)$ \\
\hline & Seriously sick & $2.7055^{* * *}$ & $2.3421^{* * *}$ \\
\hline & & $(0.3974)$ & $(0.3302)$ \\
\hline \multirow[t]{2}{*}{ Sex } & & $-0.2234^{* * *}$ & $-0.0586^{*}$ \\
\hline & & $(0.0611)$ & $(0.0328)$ \\
\hline \multirow[t]{2}{*}{ Marital status } & & 0.1008 & 0.0230 \\
\hline & & $(0.0807)$ & $(0.0451)$ \\
\hline \multirow[t]{5}{*}{ Age } & & $0.0118^{* * *}$ & 0.0023 \\
\hline & & $(0.0037)$ & $(0.0021)$ \\
\hline & Junior high school & 0.1301 & $0.1119^{* *}$ \\
\hline & & $(0.0952)$ & $(0.0487)$ \\
\hline & High school & $0.2558^{* *}$ & $0.1555^{* * *}$ \\
\hline \multirow{5}{*}{ Education } & & $(0.1114)$ & $(0.0551)$ \\
\hline & Technical secondary school & $0.3240 * *$ & $0.2026^{* * *}$ \\
\hline & & $(0.1369)$ & $(0.0666)$ \\
\hline & Junior college & $0.3589 * *$ & $0.2911 * * *$ \\
\hline & & $(0.1747)$ & $(0.0819)$ \\
\hline \multirow[t]{2}{*}{ Ln (family income) } & & 0.0380 & $-0.0596^{* *}$ \\
\hline & & $(0.0524)$ & $(0.0285)$ \\
\hline \multirow[t]{2}{*}{ Ln (work time) } & & - & 0.0133 \\
\hline & & - & $(0.0194)$ \\
\hline \multirow[t]{2}{*}{ Hukou } & & - & -0.0053 \\
\hline & & - & $(0.0456)$ \\
\hline \multirow{5}{*}{ Region } & Central & -0.1012 & $0.1646^{* * *}$ \\
\hline & & $(0.0903)$ & $(0.0392)$ \\
\hline & Western & 0.0302 & $0.3989^{* * *}$ \\
\hline & & $(0.1536)$ & $(0.0508)$ \\
\hline & Intercept & $4.5144^{* * *}$ & $0.8773^{* * *}$ \\
\hline \multirow{3}{*}{ Lambda/Sigma } & & $(0.4806)$ & $(0.2504)$ \\
\hline & & $2.1852 * * *$ & - \\
\hline & & $(0.6806)$ & - \\
\hline Wald $\chi_{* * *}^{2}=254.27$ & & & $N=7300$ \\
\hline
\end{tabular}


Table 4. Tobit regression results for migrant workers' medical burden.

\begin{tabular}{|c|c|c|c|}
\hline Variable & Variable Types & Coefficient & Marginal Effect \\
\hline \multirow{5}{*}{ Medical insurance } & NRCMS & $\begin{array}{c}-0.7748^{* * *} \\
(0.1080)\end{array}$ & $\begin{array}{c}-0.0269 * * * \\
(0.0041)\end{array}$ \\
\hline & Employment medical care & $\begin{array}{c}-2.0348 * * * \\
(0.1597)\end{array}$ & $\begin{array}{c}-0.0726^{* * *} \\
(0.0067)\end{array}$ \\
\hline & Public health services & $\begin{array}{c}-1.5146^{* * *} \\
(0.1975)\end{array}$ & $\begin{array}{c}-0.0535^{* * *} \\
(0.0078)\end{array}$ \\
\hline & Other single medical insurance & $\begin{array}{c}-1.5216^{* * *} \\
(0.1729)\end{array}$ & $\begin{array}{c}-0.0537^{* * *} \\
(0.0067)\end{array}$ \\
\hline & Multiple insurance & $\begin{array}{c}-1.5587^{* * *} \\
(0.1584)\end{array}$ & $\begin{array}{c}-0.0551^{* * *} \\
(0.0066)\end{array}$ \\
\hline SRH & & $\begin{array}{c}-0.1358^{* * *} \\
(0.0503)\end{array}$ & $\begin{array}{c}-0.0048^{* * *} \\
(0.0018)\end{array}$ \\
\hline \multirow[t]{2}{*}{ Morbidity } & Fairly sick & $\begin{array}{c}-0.2103 * \\
(0.1137)\end{array}$ & $\begin{array}{c}-0.0074 * \\
(0.0040)\end{array}$ \\
\hline & Seriously sick & $\begin{array}{c}-0.5530 * * * \\
(0.1304)\end{array}$ & $\begin{array}{c}-0.0196^{* * *} \\
(0.0048)\end{array}$ \\
\hline Sex & & $\begin{array}{l}-0.0827 \\
(0.0753) \\
\end{array}$ & $\begin{array}{l}-0.0029 \\
(0.0026) \\
\end{array}$ \\
\hline Marital status & & $\begin{array}{l}0.2176^{* *} \\
(0.1020)\end{array}$ & $\begin{array}{c}0.0076^{* *} \\
(0.0036)\end{array}$ \\
\hline Age & & $\begin{array}{c}-0.0121 \text { ** } \\
(0.0048)\end{array}$ & $\begin{array}{c}-0.0004^{* *} \\
(0.0002)\end{array}$ \\
\hline \multirow{4}{*}{ Education } & Junior high school & $\begin{array}{l}-0.0966 \\
(0.1208)\end{array}$ & $\begin{array}{l}-0.0034 \\
(0.0042)\end{array}$ \\
\hline & High school & $\begin{array}{c}-0.2673^{* *} \\
(0.1321)\end{array}$ & $\begin{array}{c}-0.0094 * * \\
(0.0046)\end{array}$ \\
\hline & Technical secondary school & $\begin{array}{l}-0.1913 \\
(0.1533)\end{array}$ & $\begin{array}{l}-0.0067 \\
(0.0054)\end{array}$ \\
\hline & Junior college & $\begin{array}{l}-0.1375 \\
(0.1790) \\
\end{array}$ & $\begin{array}{r}-0.0048 \\
(0.0063) \\
\end{array}$ \\
\hline Ln (family income) & & $\begin{array}{l}-0.0075 \\
(0.0618) \\
\end{array}$ & $\begin{array}{l}-0.0003 \\
(0.0022)\end{array}$ \\
\hline Hukou & & $\begin{array}{l}-0.1500 \\
(0.1033) \\
\end{array}$ & $\begin{array}{l}-0.0053 \\
(0.0036) \\
\end{array}$ \\
\hline \multirow{3}{*}{ Region } & Central & $\begin{array}{c}0.4814^{* * *} \\
(0.0955)\end{array}$ & $\begin{array}{c}0.0170 * * * \\
(0.0034)\end{array}$ \\
\hline & Western & $\begin{array}{c}0.7120 * * * \\
(0.1264)\end{array}$ & $\begin{array}{c}0.0250 * * * \\
(0.0045)\end{array}$ \\
\hline & Intercept & $\begin{array}{c}4.3401^{* * *} \\
(0.5596)\end{array}$ & - \\
\hline Lambda/Sigma & & $\begin{array}{c}1.4800 * * * \\
(0.0645)\end{array}$ & - \\
\hline $\begin{array}{c}\text { Observations } \\
\text { Pseudo } R^{2} \\
\text { F }\end{array}$ & & $\begin{array}{c}4734 \\
0.0988 \\
17.30\end{array}$ & \\
\hline
\end{tabular}


Table 5. Probit regression results for migrant workers' preventive medical service utilization.

\begin{tabular}{|c|c|c|}
\hline Variable & Variable Types & Coeff./Std. Err. \\
\hline \multirow{5}{*}{ Medical insurance } & NRCMS & $\begin{array}{c}0.1730 * * * \\
(0.0385)\end{array}$ \\
\hline & Employment medical care & $\begin{array}{c}0.6025^{* * * *} \\
(0.0762)\end{array}$ \\
\hline & Public health services & $\begin{array}{c}0.3943^{* * * *} \\
(0.1065)\end{array}$ \\
\hline & Other single medical insurance & $\begin{array}{c}0.4164^{* * *} \\
(0.0840)\end{array}$ \\
\hline & Multiple insurance & $\begin{array}{c}0.6768^{* * *} \\
(0.0820)\end{array}$ \\
\hline SRH & & $\begin{array}{c}0.0177 \\
(0.0231)\end{array}$ \\
\hline \multirow[t]{2}{*}{ Morbidity } & Fairly sick & $\begin{array}{c}0.1199 * * \\
(0.0602)\end{array}$ \\
\hline & Seriously sick & $\begin{array}{c}0.2649 * * * \\
(0.0804)\end{array}$ \\
\hline Sex & & $\begin{array}{c}0.0173 \\
(0.0336)\end{array}$ \\
\hline Marital status & & $\begin{array}{l}-0.0623 \\
(0.0460)\end{array}$ \\
\hline Age & & $\begin{array}{c}-0.0152 * * * \\
(0.0022)\end{array}$ \\
\hline \multirow{4}{*}{ Education } & Junior high school & $\begin{array}{c}0.0280 \\
(0.0536)\end{array}$ \\
\hline & High school & $\begin{array}{c}0.2029^{* * *} \\
(0.0583)\end{array}$ \\
\hline & Technical secondary school & \\
\hline & Junior college & $\begin{array}{c}0.2039^{* * *} \\
(0.0825)\end{array}$ \\
\hline Ln (family income) & & $\begin{array}{l}-0.0384 \\
(0.0307)\end{array}$ \\
\hline Hukou & & $\begin{array}{c}0.0457 \\
(0.0480)\end{array}$ \\
\hline \multirow{3}{*}{ Region } & Central & $\begin{array}{c}-0.2594^{* * *} \\
(0.0409)\end{array}$ \\
\hline & Western & $\begin{array}{c}-0.4409 * * * \\
(0.0538)\end{array}$ \\
\hline & Intercept & $\begin{array}{l}-0.0790 \\
(0.2582)\end{array}$ \\
\hline Pseudo $R^{2}=0.059$ & Wald $\chi^{2}=462.28^{* * *}$ & $N=7300$ \\
\hline
\end{tabular}

The impacts of other control variables on the probability of migrant workers receiving medical consultations and incurring medical expenses are as follows:

(1) SRH and disease severity. Table 2 suggests that, if the SRH of migrant workers is better, then the probability of migrant workers receiving medical consultations and incurring medical expenses is lower after controlling for other variables. The probability of receiving medical consultations and incurring medical expenses increases among migrant workers with severe diseases compared with those who were "healthy or less ill."

(2) Sex. Contrary to Lü and Wang (2012) [25], we found that women had higher probabilities of receiving medical consultations and incurring medical expenses than men. Female migrant workers face more health risks than male migrant workers; therefore, household medical resource allocation is biased toward women.

(3) Age. The impacts of age on the probabilities of migrant workers receiving medical consultations and incurring medical expenses are positive (the former is not statistically significant), indicating that 
the depreciation of health capital increases with age. Elderly individuals must spend more on medical expenses to compensate for health capital depreciation to maintain their health.

(4) Education. With increasing education, the probabilities of migrant workers receiving medical consultations and incurring medical expenses increase (the latter is not statistically significant). On the one hand, highly educated residents tend to have higher incomes and can pay for medical services; on the other hand, they usually have more medical information and can efficiently improve their health [26].

(5) Family income. In the overall sample, household income has a statistically significant negative effect on the probability of migrant workers' receiving medical consultations, while the impact on medical expenditure is statistically significantly positive, indicating that household income has a twofold effect. The health effect suggests that high-income people may have a good health status and a lower probability of becoming ill, and the wealth effect indicates that they have the ability to pay for medical expenses once they become ill, which is consistent with Liu et al. (2003) [27]. These findings also suggest that low-income people face budget constraints in medical consumption, leading them to forgo medical treatment after becoming sick.

\subsection{Heckman Regression Results for Migrant Workers' Medical Expenditure}

The inverse Mills ratio (IMR) of the Heckman model was statistically significant at the $1 \%$ significance level, indicating that the samples exhibit self-selection; that is, some migrant workers should seek medical treatment but do not.

The results of the Heckman model shown in Table 3 are similar to those of the TPM model shown in Table 2. While the coefficients of the NRCMS, family income, and regional characteristic variables decreased and were statistically nonsignificant, the coefficients of other variables increased and were statistically significant, and working hours showed no crowding out effect on medical treatment.

\subsection{Tobit Regression Results for Migrant Workers' Medical Burden}

Compared to migrant workers who do not participate in any medical insurance, those participating in employment medical care, public health services, the NRCMS, and other medical insurance and those with repeated participation in insurance have a significantly lower medical burden, as shown in Table 4.

Table 4 also shows that migrants with good SRH and a high household income have low medical burdens. However, the coefficients of age and disease severity seem counterintuitive, indicating that the proportion of OOP medical care costs decreased with age and disease severity. As shown by the TPM and Heckman results, medical expenditure increased with disease severity. For SHI, a reimbursement line exists, which dictates that people can receive reimbursement only when medical expenses for critical illness and inpatient services reach a certain reimbursement threshold. Therefore, for mild illnesses, people need more outpatient services, pay low outpatient OOP costs, and obtain low reimbursements or even no medical insurance subsidies, but for serious illnesses, medical expenses increase up to the reimbursement line such that people can receive medical subsidies. In addition, elderly people have a higher probability of critical illness than their younger counterparts. For these reasons, the proportion of medical reimbursement increases with age and disease severity.

Furthermore, we found that among migrant workers who have been reimbursed by SHI, 47 people in a "severely ill" condition spent 6308.02 yuan on annual medical expenditure and 3372.34 yuan on annual OOP costs on average and that these values were far higher than the average annual medical expenditure ( 885.25 yuan) in the overall sample. For the medical burden variable, the average burden of 47 people in a "severely ill" condition was 0.925 , which is lower than the average of 0.955 in the overall "ill" sample. Clearly, "severely ill" people spend more on medical care, but the reimbursement ratio was higher than average, which is also consistent with the Chinese basic SHI security goals intended to benefit groups with serious illnesses. 


\subsection{Probit Regression Results for Migrant Workers' Preventive Medical Service Utilization}

As shown in Table 5, any insurance can statistically significantly improve the probability of migrant workers' preventive medical service utilization, especially employment medical care and repeated participation in insurance. As disease severity and education increase, the probability of migrant workers' utilization of preventive medical services increases, while SRH has no statistically significant effect. Regional differences in preventive medical service utilization also exist for migrant workers; those in the western and central regions attach less importance to such utilization than those in the eastern region.

Qin et al. (2014) illustrate that participating in medical insurance can promote people's utilization of preventive medical resources by enhancing their health awareness [1]. While public health services and several commercial insurance programs stipulate regular medical examinations, other SHI programs have no clear reimbursement mechanism for routine medical examinations. As a result, young and highly educated people focus more on preventive health care than do elderly people.

\section{Conclusions and Policy Implications}

\subsection{Main Conclusions}

Drawing on data from the RUMiC Project survey, this paper examines the effects of health insurance on migrant workers' utilization of routine medical services, the medical burden, and the utilization of preventive medical services using a TPM, the Heckman model, the Tobit model, and a probit model. The main conclusions are as follows:

(1) Chinese SHI has not yet covered all migrant workers, and the NRCMS accounts for the main proportion of the types of medical insurance in which they participate. Participating in medical insurance is helpful to increase the probability of migrant workers receiving a medical consultation. Unlike other medical insurance programs that positively affect migrant workers' medical expenditure, the NRCMS fails to play an effective role. The possible reasons are that the NRCMS requires migrant workers to cover medical expenses and receive reimbursement after returning to their hometowns, which is a cumbersome procedure for migrant workers. SRH and disease severity have significant impacts on the medical expenditure of migrant workers, indicating that their medical care consumption corresponds to maintaining their basic health. In other words, migrant workers usually demand health services after suffering an illness shock, which may exceed their economic means.

(2) Participating in medical insurance significantly reduces migrant workers' medical burden, especially those with serious illnesses, which is also consistent with the Chinese basic SHI security goals intended to benefit groups with serious illnesses. However, in the overall sample, the proportions of medical subsidies and medical insurance reimbursement are quite low. SHI seems to play a role in decreasing the medical burden, but the coverage and reimbursement proportions are narrow and low in this case.

(3) Participating in medical insurance (especially employment medical care and repeated participation in insurance) can statistically significantly improve the probability of migrant workers' preventive medical service utilization. High-income migrant workers have a low probability of illness, but their medical expenses are high once they become ill. On the one hand, a restraining effect may cause migrant workers to fully abandon medical service demands due to constraints on income and SHI. On the other hand, low-income migrant workers are vulnerable in terms of physical health and are consequently prone to illness.

\subsection{Policy Implications}

Based on the findings above, expanding the reimbursement scope of SHI and gradually establishing a comprehensive SHI system to address both serious and minor illnesses seem to be the first priorities for the Chinese government. The basic goal of Chinese SHI is to benefit groups with serious illnesses, which is helpful for migrant workers with these conditions but neglects low-cost outpatient treatment. 
Migrant workers often self-select into a group with good health conditions such that their main demand for medical services is to address the daily risk of minor illness. Moreover, protecting against both outpatient and inpatient illnesses is more effective than only protecting against serious illnesses since such protection can promote migrant workers' early consultation and treatment and reduce the phenomenon of ongoing minor illness and burdensome serious illnesses. However, the expansion of the reimbursement scope of SHI corresponds to rising premiums, which is a considerable burden for migrant workers because of their low incomes. Therefore, the government should consider urban and rural economic development and affordability to gradually establish a comprehensive SHI system to protect people with both major and minor illnesses.

Second, reducing the barriers to building an urban-rural unified SHI system and a convenient and fast reimbursement procedure would be another valuable strategy to address related issues. Doing away with multiple participation in SHI for migrant workers is essential for avoiding overlaps in insurance, preventing medical resource waste, and reducing migrant workers' economic burden. In addition, establishing a convenient and fast reimbursement procedure for migrant workers is important because of their occupational characteristics, the uncertainty of disease occurrence, and the timeliness of treatment, and will also increase the possibility of migrant workers participating in SHI.

Finally, more than $30 \%$ of migrant workers are not covered by any SHI. Among insured migrant workers, the proportion of those who receive medical subsidies is only $11.5 \%$, and the average medical insurance reimbursement ratio is only $5 \%$, indicating that participating in insurance has a significant impact on migrant workers' medical treatment under the current Chinese SHI system and that the government should not only expand the reimbursement scope of SHI, but also ensure that migrant workers can benefit from SHI, which will improve their opportunities to participate in SHI.

Undeniably, significant differences in the utilization of medical services and medical insurance requirements exist due to the complex composition of migrant worker groups, including differences in age, culture, and income. The uniform standards of SHI will result in some migrant workers abandoning participation in SHI or some SHI participants failing to meet the requirements for effective medical insurance utilization. Therefore, establishing a unified urban-rural SHI system remains an urgent issue $[28,29]$.

Author Contributions: Resources, Y.Z.; Writing - original draft, F.Z.; Writing - review \& editing, X.S. Note that X.S. is the corresponding author of this paper. All authors have read and agreed to the published version of the manuscript. The authors appreciate the Chinese Household Income Project (CHIP) for providing data.

Funding: This research was funded by the project of Zhejiang Provincial Natural Science Foundation, China (No.LY17G030013) and the Provincial Think Tank Research Project at China Academy for Rural Development, Zhejiang University (No. zjxxzk19).

Conflicts of Interest: The authors declare no conflict of interest.

\section{References}

1. Qin, X.Z.; Pan, J.; Liu, G.G. Does Participating in Health insurance benefit the migrant workers in China? An empirical investigation. China Econ. Rev. 2014, 30, 263-278. [CrossRef]

2. Yip, W.; Hsiao, W.; Chen, W.; Hu, S.; Ma, J.; Maynard, A. Early appraisal of China's huge and complex health-care reforms. Lancet 2012, 379, 833-842. [CrossRef]

3. Meng, Q.; Xu, L.; Zhang, Y.; Qian, J.; Cai, M.; Xin, Y.; Gao, J.; Xu, K.; Boerma, J.T.; Barber, S.L. Trends in access to health services and financial protection in China between 2003 and 2011: A cross-sectional study. Lancet 2012, 379, 805-814. [CrossRef]

4. Fu, W.; Zhao, S.; Zhang, Y.; Chai, P.; Goss, J. Research in health policy making in China: Out-of-pocket payments in Healthy China 2030. BMJ 2018, 360, k234. [CrossRef]

5. Qin, L.; Chen, C.P.; Liu, X.; Wang, C.; Jiang, Z. Health Status and Earnings of Migrant Workers from Rural China. China World Econ. 2015, 23, 84-99. [CrossRef]

6. Chen, X.-Y.; Jin, X.-Y. A Study on Medical Aid for Migrant Workers. J. Zhejiang Univ. (Humanit. Soc. Sci.) 2006, 6, 128-135. 
7. Cutler, D.M.; Zeckhauser, R.J. Chapter 11 The anatomy of health insurance. In Handbook of Health Economics; Culyer, A.J., Newhouse, J.P., Eds.; Elsevier Science: Amsterdam, Holland, 2000; Volume 1, pp. 563-643.

8. Currie, J.; Gruber, J. Health insurance eligibility, utilization of medical care, and child health. Q. J. Econ. 1996, 111, 431-466. [CrossRef]

9. Lichtenberg, F.R. The Effects of Medicare on Health Care Utilization and Outcomes. Forum Health Econ. Policy 2002, 5, 27-52. [CrossRef]

10. Hadley, J. Sicker and poorer-The consequences of being uninsured: A review of the research on the relationship between health insurance, medical care use, health, work, and income. Med Care Res. Rev. 2003, 60, 3S-75S. [CrossRef]

11. Finkelstein, A.; McKnight, R. What did Medicare do? The initial impact of Medicare on mortality and out of pocket medical spending. J. Public Econ. 2008, 92, 1644-1668. [CrossRef]

12. Wagstaff, A.; Lindelow, M.; Gao, J.; Xu, L.; Qian, J.X. Extending Health insurance to the rural population: An impact evaluation of China's new cooperative medical scheme. J. Health Econ. 2009, 28, 1-19. [CrossRef]

13. Lei, $\mathrm{X}$.; Lin, W. The new cooperative medical scheme in rural china: Does more coverage mean more service and better health? Health Econ. 2009, 18, S25-S46. [CrossRef]

14. Cheng, L.; Zhang, Y. The New Rural Cooperative Medical Scheme: Financial Protection or Health Improvement? Econ. Res. J. 2012, 1, 120-133.

15. Pan, J.; Lei, X.; Liu, G. Does Health Insurance Lead to Better Health? Econ. Res. J. 2013, 4, 130-156.

16. Yang, W.; Wu, X. Paying for outpatient care in rural China: Cost escalation under China's New Co-operative Medical Scheme. Health Policy Plan. 2014, 30, 187-196. [CrossRef]

17. Zhou, Q.; Qin, X.-Z.; Yuan, Y. Migrant workers' real accessibility to medical services: Based on the special survey of rural-to-urban migrant workers in Beijing. Insur. Stud. 2013, 9, 112-119. [CrossRef]

18. Heckman, J. Sample selection bias as a specification error. Econometrica 1979, 47, 153-161. [CrossRef]

19. Xie, S.; Wang, J.; Chen, J.; Ritakallio, V.M. The effect of health on urban-settlement intention of rural-urban migrants in China. Health Place 2017, 47, 1-11. [CrossRef]

20. Gao, Q.; Yang, S.; Li, S. Labor contracts and social insurance participation among migrant workers in China. China Econ. Rev. 2012, 23, 1195-1205. [CrossRef]

21. Akgü, M.; Giulietti, C.; Zimmermann, K.F. The RUMiC longitudinal survey: Fostering research on labor markets in China. IZA J. Labor Dev. 2014, 3, 5. [CrossRef]

22. Kong, S.T. Rural-urban migration in China: Survey Design and Implementation. In The Great Migration: Rural-Urban Migration in China and Indonesia; Meng, X., Manning, C., Li, S., Effendi, T., Eds.; Edward Elgar Publishing: Cheltenham, UK, 2010; pp. 135-150.

23. Hadley, J.; Waidmann, T. Health insurance and health at age 65: Implications for medical care spending on new medicare beneficiaries. Health Serv. Res. 2006, 41, 429-451. [CrossRef] [PubMed]

24. Bannai, A.; Tamakoshi, A. The association between long working hours and health: A systematic review of epidemiological evidence. Scand. J. Work Environ. Health 2014, 40, 5-18. [CrossRef] [PubMed]

25. Lü, M.; Wang, Y. An empirical study on rural resident's demand for medical services in China: With the model of four-part model. Chin. Rural Econ. 2012, 6, 59-71.

26. Kenkel, D.S. The demand for preventive medical care. Appl. Econ. 1994, 26, 313-325. [CrossRef]

27. Liu, G.G.; Wu, X.; Peng, C.; Fu, A.Z. Urbanization and health care in rural China. Contemp. Econ. Policy 2003, 21, 11-24. [CrossRef]

28. Fang, P.; Dong, S.; Xiao, J.; Liu, C.; Feng, X.; Wang, Y. Regional inequality in health and its determinants: Evidence from China. Health Policy 2010, 94, 14-25. [CrossRef]

29. Yu, H. Universal health insurance coverage for 1.3 billion people: What accounts for China's success? Health Policy 2015, 119, 1145-1152. [CrossRef]

(C) 2020 by the authors. Licensee MDPI, Basel, Switzerland. This article is an open access article distributed under the terms and conditions of the Creative Commons Attribution (CC BY) license (http://creativecommons.org/licenses/by/4.0/). 